\title{
How Organization Will Enhance Benefits Realization by Using Innovation Project Managment and Al (Artificial Intilligence)
}

\section{The Influence of Innovation Project Management on Project Success within Projects-Based Organizations}

\author{
Tarek Tawfik ${ }^{1}$, Jamila Al Maazmi ${ }^{2}$ and Omran Al Shamsi ${ }^{3}$
}

1 Dubai Electricity and Water Authority, Dubai, United Arab Emirates, tarek.mohamed@dewa.gov.ae

2 Dubai Electricity and Water Authority, Dubai, United Arab Emirates, Jamila.Juma@dewa.gov.ae

3 Dubai Electricity and Water Authority, Dubai, United Arab Emirates, Omran.AlShamsi@dewa.gov.ae

\begin{abstract}
The importance role of innovation and technology is widely recognized in the corporate change, growth and profitability, but the main challenge is how to facilitate the innovative process and tools for practices and research, especially in project-based organizations. Where, conventional project management methods are oftentimes insufficient for managing innovation projects. In project-based firms, innovation is almost lost under the pre-determined scope and predicted environments of traditional project management. There is tremendous pressure on organization to innovate and the project managers are responsible to manage these innovation projects effectively. Therefore, innovation project management calls for providing the tools and technology (Al), perceptions, and metrics needed; in order to manage innovation projects successfully; helping PM's and stakeholders to identify problems in their organization, conceive elegant solutions, and, when necessary promote changes to their organizational culture. Thus, for this paper, authors attempt to conceptualize the innovation project management; to facilitate the innovation within project environment and to gain the ultimate corporate goals through their projects accomplishment.
\end{abstract}

(C) 2020 The Authors. Published by Budapest University of Technology and Economics \& Diamond Congress Ltd Peer-review under responsibility of the Scientific Committee of the Creative Construction Conference 2020.

Keywords: project-based organization, project management, innovation management, innovation project management, project success

\section{Introduction}

All companies desire growth. But without some innovations, the opportunities may be limited and even if the firm does have a successful innovation, failure can still occur if the company focuses on past successes without developing a culture for continuous and sustainable innovations, Today industry leaders can become tomorrow's failures without constantly challenging results [12].

If continuous and sustainable innovation is to occur, then innovation leadership and project management must be integrated together and with a clear understanding of each other's roles. Innovations defines what we would like to do, and project management determines if it can be done. The integration also may require that both parties learn new skills and create a corporate culture that support ideas management practices. Understanding each other's roles is the first step in making a company more innovative. This requires that the project managers and other innovation personnel understand what they do not do now but must do 
for long-term successful innovation. "The Future is a direction, not a destination", as quoted by Edwin Catmull $[5,12,25]$.

Over the past three decades, there has been a great deal of literature published on innovation and innovation management. Unfortunately, innovation projects may not be able to be managed effectively using the traditional project management philosophy we teach in project management courses. Innovation varies from industry to industry, and even companies within the same industry cannot come to an agreement on how innovation project management should work. Part of disagreement comes from the fact that there are several forms of innovation, each one with different characteristics and possibly requiring different tools $[5,12,25,26]$.

It is inevitable that, over the next several years, professional organizations such as the Project Management Institute (PMI) will recognize the need to begin setting some standards for innovation project management and possibly partner with organizations, such as the Product Development and Management Association (PDMA), with offer a certification programs related to innovation. There may also appear an Innovation Project Management Manifesto like the Agile Manifesto. The greatest innovation in the next decade may be the recognition and advancement of innovation project management such as a specialized project management career path position [5,12,25].

There are difference between traditional and innovation project management. People have avoided using the words "innovation" and "Project Management" in the same sentence because of these differences. There is limited research on examine the link between innovation and project management. Innovation is often unstructured and requires people to utilize those portions of the brain that focus on freethinking, creativity, brainstorming, and alternative analysis. Project Managers, on the other hand, is very structured, with a well-defined scope, and often with a very tolerance for any creativity or brainstorming that is believed to be out of scope [12].

Also, in past days, project management research has focused a lot on practices that related to get projects done rather than on conceptual or strategic issues like innovation where reasons for success, exposes that the most common subjects for project management research are those linked to initiating, executing and closing projects [9].

There are several types of innovation, ranging from small, incremental changes to product to very new products and processes that are the result of a breakthrough in technology that disrupts the market. Incremental innovation may follow some of the standard project management processes. Radical or disruptive innovation may require playing a different set of rules. All assumptions must be challenges, even if they appear in a business case. Innovation requires the identification of the right problems and thinking about elegant solutions. All of these factors may require that the organizational culture change. "If you want something new, you have to stop doing something old", as quoted by Peter Drucker [12].

Therefore, this paper purpose is to fine the linkage between the project management and innovation management and attempt to map them together; to assess their merging influence on project success and to improve the business outcomes, in order to compete and survive in this new market place.

\section{Theoretical background}

A different type of forces drive the innovation process, for instance the demand for radically new types of structures or buildings, especially during the $80 \mathrm{~s}$ and $90 \mathrm{~s}$. This demand for new types of buildings was developed by the diffusion of information and communication technology, growth of the service sector, and new methods of manufacturing. All that, to enhance flexibility to meet unforeseen changes in demand and to improve lifecycle performance characteristics [7].

Moreover, global business is susceptible to changes in technology (ex. Artificial Intelligence), demographics, a turbulent political climate, industrial maturity, unexpected events, and other factors that can affect competitiveness. Taking advantage of these changes will be challenging. Companies need growth for longterm survival. Companies cannot grow simply through cost reduction and reengineering efforts that are 
more aligned to a short-term solution. In addition, companies are recognizing that brand loyalty accompanied by a higher level of quality does not always equate to customer retention unless supported by some innovations [12].

\subsection{Project-based organizations characteristics}

Project-based firms definition according to many literature as firms that are organized around projects [7] and that produce knowledge-intensive services or complex integrated systems by order of their clients [9].

Based on many studies related to project-based management, there are at least four exceptional features, comparing to other practices of management [19]:

- Project-based management is focused toward activities to accomplish goals of time, scope, and cost [20] and, gradually, toward wider business and customer objectives. In previous study, management by objectives has been considered as an organizational innovation, also as goal-oriented agendas.

- Project-based management induces replacing the old organizational structure or utilizing a temporary organizational structure [20]. In the past, matrix or M-form organizational structures, and flow manufacturing in multiple plants have been studied as organizational innovations.

- Project-based management can contain both organization-specific and standardized tools and good practices [20]. So earlier, studies on ISO 9000 and total quality management (TQM) have been considered as organizational innovations.

- Project-based management endorses distributed and project specific responsibilities in the organization [20]. Each project has a dedicated project manager and project organization that dissolves as the project ends. New management system has earlier been considered as organizational innovation in somewhat different settings.

Organizational innovation may cover new services or products, new organizational structures or administrative systems, new process technologies, or new plans or programs relating to organizational participants [19].

Project-based organizations must manage uncertainty and technological across whole organization, within networks of interdependent regulatory bodies, customers and suppliers. Project-based firms therefore need to manage in multi-technology environments, responding to changes in engineering, software, information and materials technologies, increasing costs, and the need to deal with growing complexity because of political and social situations. However, management of innovation is complicated, since there is a discontinuous nature of project-based production in which, often, there are broken learning and feedback loops [7].

Likewise, according to [6] most actions in recent business world are planned and organized in projects still there is no universal project procedure that fits all organizations. Specially, that innovation are frequently applied via projects. Therefore, innovation project is a novel way to do so and aims to take something that has been planned, created, or developed and then utilizes processes to them in some way to realize a specific outcome. Consequently, the need for innovation in project-based organization is desirable.

\subsection{Innovation and management}

According to [23], innovation studies are derived from some important studies of Joseph Schumpeter in the 20 s and 30s, whose ideas started to gain popularity in the 60s, as the general interest among policymakers and scholars in technological change, R\&D and innovation increased. The field formed as a distinctive academic discipline from the 80 s.

Basically, the innovation process model with a standard decision points of five-stage model is consist of creativity, selection, incubation, implementation and learning. First, the creativity stage involves examining the internal and external environment: customers' needs, competitors' products and in-house R\&D can all be sources of creativity. Second, selection stage follows as the company assesses the relative merits of 
competing ideas, considering the organization's strategy and operational constraints. Third, the incubation stage, where the company develops a prototype, using it to identify problems and resolving them before progressing to the larger scale activity of the following stages. Finally, during implementation stage, the company scales up the prototype to full production and launches the product in the market [14].

And, in order to understand innovation further more, it is required to know the source of the innovation or where they come from. Thus, the seven sources of innovation were listed as following [6]:

The first four represent the organizational internal sources:

- Innovation based on process need- Based on specific tasks within a business rather than overall operating strategy.

- The incongruity- Is the variance between actual reality and perceived/assumed reality.

- Changes in industry structure or market structure that catch everyone unawares.

- The unexpected- The unexpected success, failure or outside event.

Whereas, the next three describe organizational external sources of changes:

- New knowledge, both scientific and non-scientific.

- Changes in perception, mood and meaning.

- Demographics- population changes.

In 2016, [6], have identified five types of innovations:

- New sources of supply - input innovation

- New production methods (process)

- New forms of organization

- New product

- New market

Based on [15] (p. 229) realized that there is a strong link between innovation and management, accordingly, the following description about innovation and management have been provided: "Management is to some extent a cross-disciplinary field by default and firm-level innovation falls naturally within its portfolio. So between innovation studies and management there clearly is some common ground" [23]. Therefore, the next sections will provide more description about project management and innovation management concepts and their relationships.

\subsection{Project management}

According to PMI's A Guide to the Project Management Body of Knowledge (PMBOK ${ }^{\circledR}$ Guide) [20] a project management, is the application of knowledge, skills, tools, and techniques to project activities to meet the project requirements. It has been practiced as a distinct profession in the mid-20th century. Project management processes fall into five clusters: initiating, planning, executing, monitoring and controlling, and closing. Moreover, project management knowledge areas are: integration, scope, time, cost, quality, procurement, human resources, communications, risk management, stakeholder management. All management know clearly about these very well. However, project management considers bringing a unique focus shaped by the goals, schedule and resources of each project.

Therefore, a project can be considered as an endeavor in which financial, human, and material resources are organized in a unique manner to commence an exclusive scope of work, of given specification, which constraints of time and cost, in order to accomplish valuable change that can be defined through quantitative and qualitative objectives [23]. 


\subsection{Innovation project management}

In this section, a brief literature review exposed the crossing point amongst project management and innovation studies, in which, there are number of important associations between project and innovation.

Thus, based on Keegan and Turner (2002, p.385), "A revision of traditional project management guidelines may be necessary given the potential of conventional approaches to managing (innovation) projects to stifle innovation" [23].

Besides, according to other scholars, the term of innovation project is used and the common definition is:

Innovation projects are systematically managed activities that use inputs in order to transform them into outputs with a certain scope and aims at achieving something new, in a new way or at improving something existing [26].

Consequently, innovation project management will be focused on a process for creating and executing management decisions that are in linked with the defined organizational strategic objectives and the organizational structure, formation of actions and monitoring their execution. In sum, focusing on all the implementation process of an innovative idea [1]. Moreover, many authors like [12] put three critical innovation interfaces as: organization, technology, and markets.

However, several researches indicates that innovation projects set the requirements that must comply with tools to manage them in the long-term period. Herewith, innovation project management must be reflected within three features, in specific, as a management decision process, as a functional system of, and as an organizational system in terms of the functional approach in the innovation project management [16].

On the other hand, authors like [1] described some more approaches related closely to innovation project management in a further comprehensive way as following:

- The system approach that refers to the management process, in which it consist of two subsystems that includes the "input" and "output" of the system, 1) the external environment, where it is communicating with the external environment, 2) and the internal environment, where it is a set of consistent mechanisms that ensure the process by which the management subject govern the process, the translation of an "input" into an "output", the system approach needs support on a number of applicable systematic sets, combined models, means, standards, processes and tools that are used for managing projects in several areas of activity.

- The process approach that refers to the management functions of project progress, planning, organization, motivation, controlling, coordination, and regulation to be interrelated and establishing a management cycle.

- The behavioural approach that refers to the actualization of the human resources and number of the principles of inspiration to accomplish the objectives of both the individual and the organization.

- The prescriptive approach that refers to the guideline of functions of the management elements by normative of the task, programs, plans, region, national government, the founder, and the organization itself.

- The integration approach that refers to the improvement of collaboration between management, expanding the relations among the gears of a management system, amongst the life cycle phases of the management object and between the management structural levels.

Based on these methods, innovation project management is managed as a process of advanced execution of an agreed set of management phases - initiation, planning, execution, analysis and regulation, monitoring and control, and closing - that guarantee meeting or even exceeding the project success [1].

\subsection{Classification of innovation projects}

There are number of classification and typologies of projects have been developed. Thus, for this paper and for the purposes of the study it is aimed to define the location of innovation projects and to state their specific groupings, see Fig. 1. There are two types of projects; the conventional projects, which is the 
traditional project that include the commonly executed ones like operational projects, constructions projects, or as infrastructural ones [6,23].

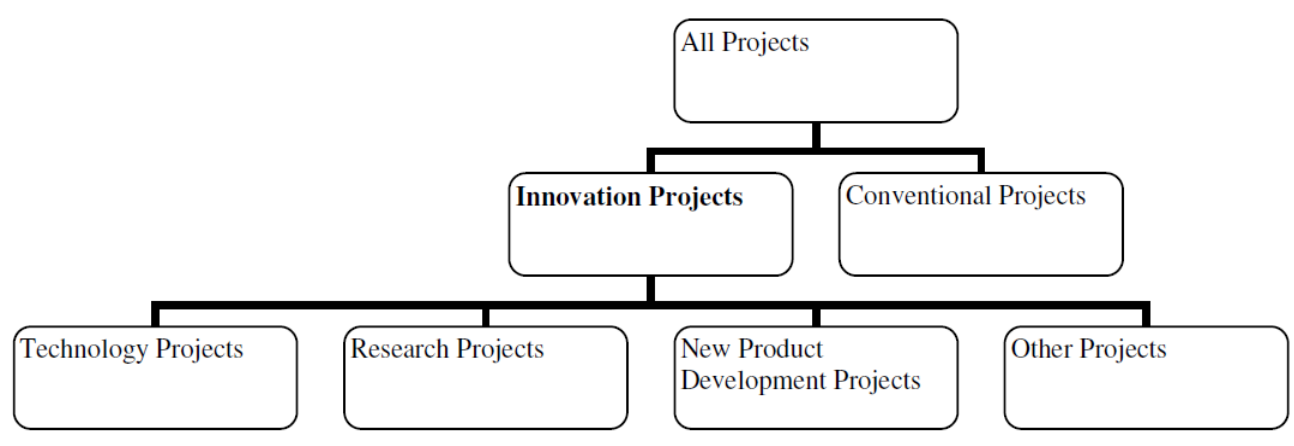

Fig. 1. Classification of projects [23]

The second type is the innovational projects that includes technology project, new product development projects, research projects, and other projects. Technology projects are refer to R\&D projects, especially in such industries as defence, aerospace, etc. In addition, research projects are refer to the projects that involved in various research, for instance for social research, not necessarily as a technological projects $[6,23]$.

\subsection{Mechanism of innovation project management}

As previously mentioned that the innovation project is a set of organizational, technical, planning, calculation and financial documents needed to achieve the project objectives. Consequently, the innovations implementation process can be defined as a collective of organizational, production, financial, technological, research, and commercial processes, which can be taken in a precise arrangement and producing innovations [16].

Likewise, the right organizational focus will be looking at projects as labs to test innovation in all dimensions. Innovation will include selecting the right mix of team members, experimenting with the right balance of virtual and collocated teams, testing new ways of working, experimenting fast with outcomes, innovating the use of data analytics in making faster and more effective decisions, and sensing very differently while engaging with the customers often and fast for best creative outcomes [12].

According to $[12,16]$ the mechanism of innovation project management had been developed in stages, as:

- Stage (1): the project objective and goals with targeted results are developed, the forecasts of the project results are well-defined, the competitive capacity and possible economic consequence are projected, activities with a complex project measurements are shaped, and the project is displayed and planned. Where, the most important step for this stage is assessment of the project excitability.

- Stage (2): the selection of organizational form of management, activities related to measure, forecast, and estimate the developed operational state to achieve required results, spending of cost, time, and resources, analysing and removing the causes of elapsing from the established plan, then plan modification are done accordantly. Fig. 2 displays the innovation project management mechanism. 


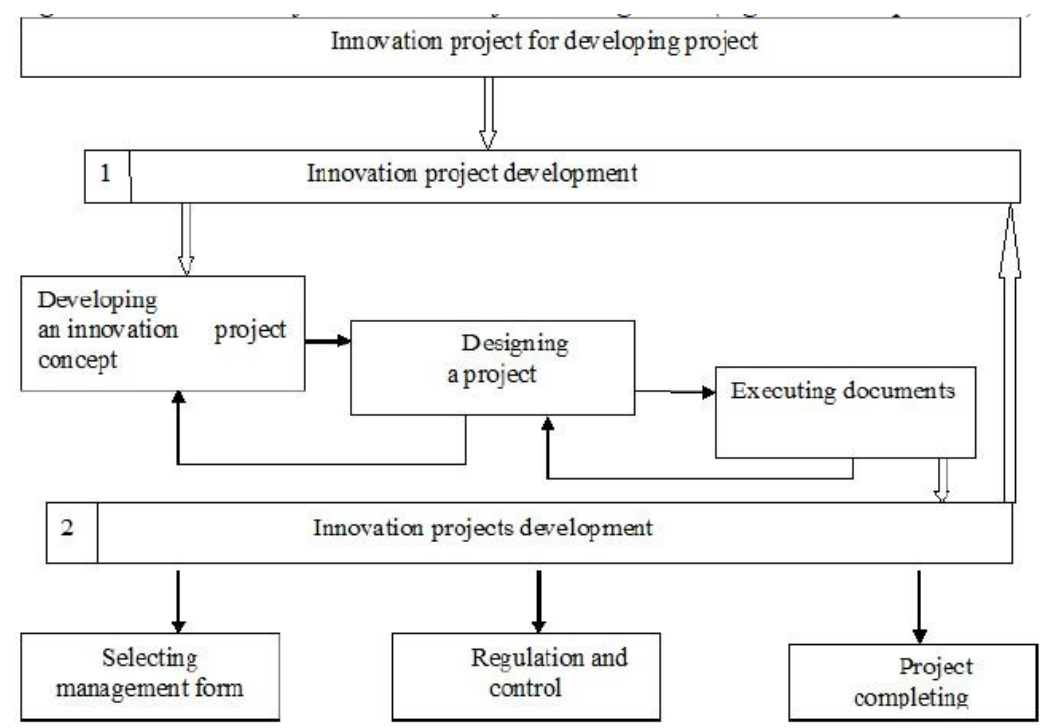

Fig. 2. The mechanism of innovation project management [16]

\subsection{Characteristics of conventional and innovation project management}

There are many characteristics can be considered when likening innovation with conventional projects. As mentioned by authors like $[6,23]$ that innovation projects by their nature are vary from conventional projects in many aspects like:

- Objectives, whereas conventional projects tend to have clearly defined goals and targets. On the opposite, innovation projects often do not. Innovation is often intangible end goals and the commercial success of an innovation project can be highly uncertain. In fact, innovation is often a result of trial-and-error.

- Expenditures for research and innovative activities are considered as long-term, with increased insecurity regarding the eventual amount of generated earnings.

- Resources in traditional project management is designed via the accuracy, precision, and optimal use of resources. However, for innovation part since it is a creative process related to uncertainty aspect it is required slack resources.

- Risk-taking is low in conventional projects since the objectives are clearly defined and processes are established. While, in innovation projects the risk-taking is high; since their objectives are lightly identified and vague, and processes are more exploratory and experimentally.

- Project teams leading innovation projects are made up of people with diverse backgrounds, and that reflect the complex nature of innovation.

\subsection{Project managers and innovation personnel challenges}

Project managers that are using innovation projects must understand that the environment of innovation is significantly different from the traditional project environment, where some critical problems and challenges may occurs like for instance [12]:

- The alignment issue of the project and decision-making toward business strategy and strategic business objectives.

- Many of the team members may be made up of partner and consumers organizations, especially if co-creation is being used.

- There is a connection among innovation project management and strategic development.

- Benefits of success may look like another way from the traditional project management.

- Project managers may be predictable to create a major amount of business decisions.

- There are variances between innovation and traditional project management. 
- Innovation project management is consider as a strategic capability.

- A long-term rather than short-term thinking might be required.

Hence, when linking the project with innovation, the biggest challenge facing project managers possibly, particularly qualified project managers, is knowing that innovation projects may need a full different set of gears and tools than they have been familiarized with [12].

\subsection{Innovation project management skills tools}

As commonly recognized from previous literature that innovation has arisen as the engine of social cohesion and national success but come with it new challenges. However to preserve global competitiveness and people's regular of living and to accommodate new challenges, efficiency needs to advance, new businesses need to be produced and people required to gain the skills that employers want. This lead to more acceptance by individuals receive change, grip new ideas, and improve new capabilities and skills. Hence, the required tool that measures the skills needed for innovation, are developed mainly to measures five general skills, which support innovative behavior and procedure an agreed number of characteristics that clearly linked to the innovation process: leadership, energy, creativity, risk-propensity, and self-efficacy [8].

In details, and compare to traditional project management, where all actions depend more in the organizational guidelines, policies, and procedures. As well as, for the project management methodology the project manager simply directs the project team to complete all the needed forms and checklists related to the project. Whereas, for innovation project management there are different skills required because of the innovation nature [12].

Few literatures identified the characteristics of innovators, but some of these studies focuses on creativity as a personality trait. Moreover, the studies assumed that innovative behaviors and skills may be gained from experience and experimentation. however, innovators may developed more skills through appropriate education and training $[8,13]$. Thus, here are some of important skills take into account for an innovation project manager like [12]:

- Knowing the firm's intangible and tangible assets (capabilities and resources)

- Willing to work under up normal pressure, risk and uncertainty

- Link the team objectives with the firm's growth objectives

- effective team building that includes external resources

- Let team members to be accountable to their actions

- Innovation Leadership and Good communicator

- Have a wide insight, see "the big" picture

- Have a design thinking skills

- Creative Problem-Solving

- Will to take responsibility

One of the most critical dimensions for projects success over the years has always been executive support. In innovation, several firms are recognised that the most critical to start from the top. For example, boards of directors and executive leaders of the future are not going to play a very different role, however they are improving, innovating, changing the business for the better, as well as, strengthening the excellence of implementation that derives from innovative project management [4,12]. Moreover, innovation in project management requires a good degree of autonomy. Specially, that today's dynamic workplace, teams are luckily becoming more self-directed. This is necessary to enhance the opportunity of creativity, the flow of ideas, and the assurance that the teams will produce the innovations desirable for the style engaged to track projects [12]. In sum, innovation is initially ran by human attempts, the appreciation and improvement of an idea adjudged to bring economic and social welfares. The process is clearly rational in that it draws on individuals' involvement and skills to translate their ideas and knowledge into something unique that will be valuable by others [8]. Fig. 3 shows the journey of the ideas until it turns into innovation. 


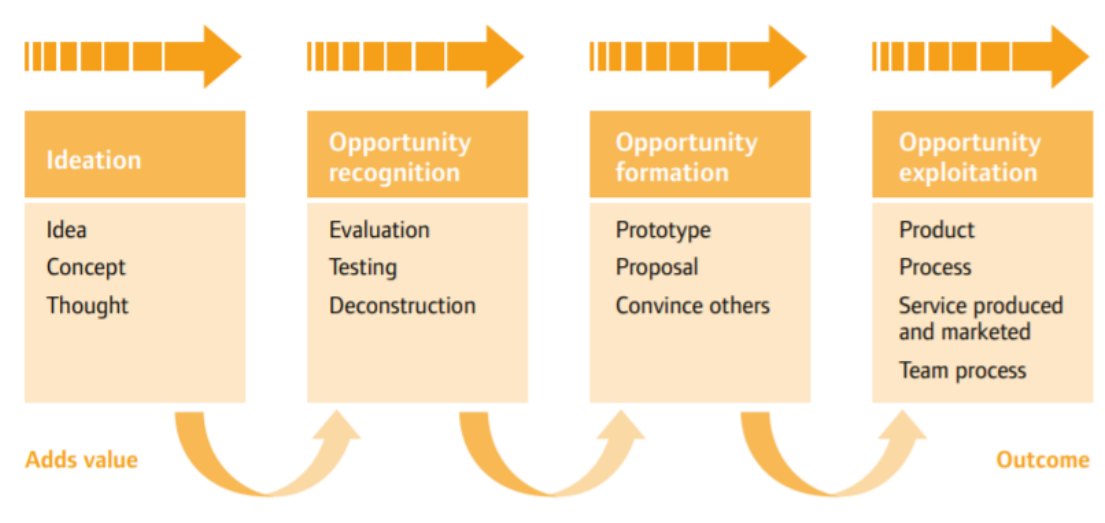

Fig. 3. How the ideas are turned into innovations [8]

\subsection{Artificial intelligent (Al) technologies}

Technological Innovation influences organizations capability to try to win effectively in a progressively more global market [2], and one of the most popular technological innovation notion in a current business world is the artificial intelligent ( $\mathrm{Al})$, which it dramatically reshape enterprise project management. Artificial intelligence (Al) tech such as deep learning and process automation is changing how projects are managed today and will have an even greater effect tomorrow. Artificial intelligence (Al) has permeated enterprise operations to the point that it now determines an organization's success, including in the area of project management [20].

According to [2] there are several essential advantages for this kind of innovation, as could computing, forensic accounting, mobile accounting, enterprise resource planning, social media, optical character recognition, and reducing errors through Tax software.

Likewise, based on [21] report found that in the next three years, project professionals expect overall $\mathrm{Al}$ usage to jump from $23 \%$ to $37 \%$ and the majority of respondents $(81 \%)$ said their organizations are currently being affected by Al technologies. The growth in Al usage will require changes in how projects are managed, and how organizations implement strategy.

The [12] report identified six Al technologies that are affecting organizations around the globe:

- Decision management: Creates an intelligent process or set of processes based on rules and logic to automate decision-making. Project managers predict that in the next three years, the impact of the following three Al technologies will grow:

- Knowledge-based systems: Understands the context of the data being processed, helping support human learning and decision-making.

- Machine learning: Analyzes data to build models by detecting patterns, yielding improved decision making with minimal human intervention.

- Deep learning: Builds, trains and tests neural networks that predict outcomes and/or classify unstructured data based on probabilities.

- Expert systems: Emulates and mimics human intelligence, skills or behavior in a particular field, topic or skill.

- Robotic process automation: Mimics and automates human tasks to support corporate processes.

\subsection{The innovation culture}

Many authors like [10] utilized the common definition of the culture for their studies, as the shared beliefs, values, norms, attitudes, ideas, and performances that define a group of people and their behavior. Organizational cultures are intangible assets that can lead to failure or success. The failure can happen when innovation makes people tense. Some people consider themselves as not creative people. Also, there are many people conclude that the innovation is not part of their job description and the innovation is the 
only related to research and development people. Some are not even convinced that innovation is significant to validate a major initiative. Therefore, the importance of an organization and or project's culture is often underestimated. As a result, the organizational innovation culture need to be boosted and acknowledge by all people within the organization; to allow people to freely contribute ideas [12].

[12] Proven that an effective innovative cultures must allow within the organization the following habits: risk taking, curiosity, failure tolerance, everyone to tap into their own level of creativity, freedom to follow one's intuition, avoid or defer from rapid judgment, collaboration (informal), active listening, being team players, managing tensions rather than just trade-offs. In another words, without the safety that is needed to innovate, organizations miss out on the right amount of innovation enablement. The culture to support innovation in project management must be adaptive. No longer would a classic view of the slow build-up of phases of a given project be suitable for generating and testing the best ideas. Much higher iteration would be needed. Teams must be encouraged to take risks and the organization must have a high tolerance for mistakes that can occur at a higher rate than ever before. The appetite for risk-taking and the courage that is required to fail and learn is the new normal. Fail fast and learn will become part of the new DNA of most organizations. The learning culture that this creates is priceless. Executive leadership will play a big role here too, as they will have to walk the talk frequently and will have to use a high level of emotional intelligence to manage the stress related to the risk taking required. Leaders will have to relate to their project managers differently to instil a new sense of trust.

\subsection{Knowledge management}

A Knowledge management definition as per [17] ( $p 3)$, is 'the deliberate and systematic coordination of an organization's people, technology, processes, and organizational structure in order to add value through reuse and innovation. This coordination is achieved through creating, sharing, and applying knowledge as well as through feeding the valuable lessons learned and best practices into corporate memory in order to foster continued organizational learning".

In 2016 [18], studied and examined the association among core requirements of innovation, knowledge management implementation, and organizational performance in a mobile telecommunications sector. The results indicated that knowledge management implementation had a statistically significant and direct positive effect on innovation. In addition, it indicated that the innovation had a positive and statistically significant effect on organizational performance. Thus, the knowledge management aspect will be consider in this paper; to control the process of innovation project management.

\subsection{Innovation project performance (success)}

In order to evaluate and to assess the innovation project success, there is a need to check the external market-related performance items. In addition, it is required to capture the match with client needs, the impact of the innovation on competitive advantage, adherence to revenue targets, and adherence to profit targets. Besides, the perceived gain in reputation in the area of the new product or new service was included, since this is an important aspect of performance in project-based firms $[3,9,24,25]$.

\subsection{Innovation project management models/measurements}

A study by [3] explored a number of themes derived from the innovation literature innovation for project management perception that consist of the following:

- Organisation of work

- The type of structure used to manage innovation projects

- The level of formality in that structure

- Patterns of authority

- Communication patterns

- Evaluation of outcomes 
Another study by [11] put a model to examine the correlation between the four dimensions of innovation management (organization culture, strategy, and structure and innovation means and tools) and the influences of internal and external factors for two detailed case studies in two medium-sized contractors. This model finding allowed a suitable management of innovation in construction companies and improved the companies' ability to innovate, see Fig. 3.

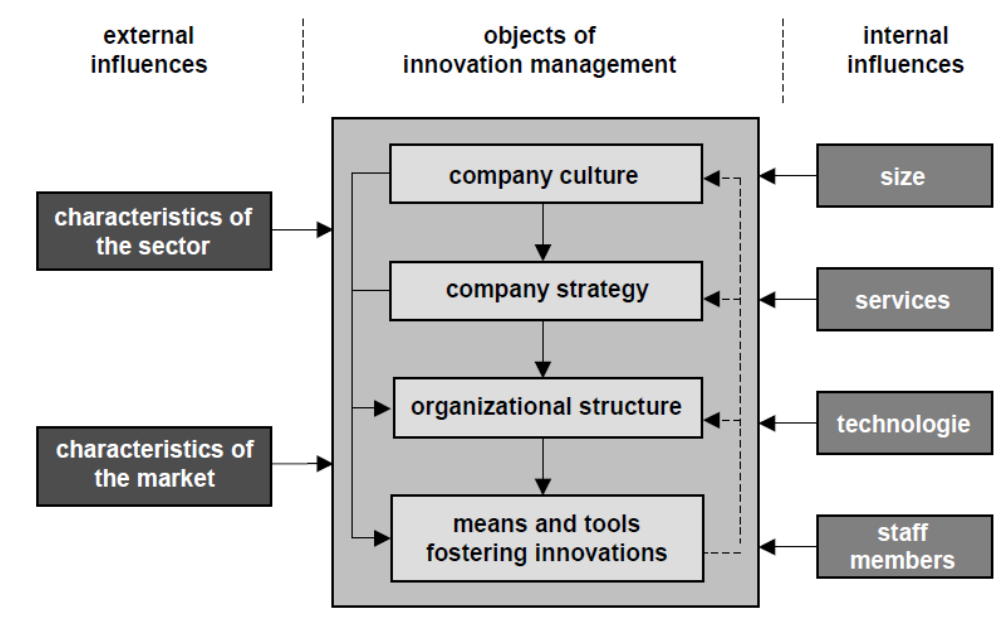

Fig. 4. The integrated model of innovation management in construction companies [11]

Then a study by [22] proposed a seven-dimensional conceptualization of the innovation management phenomenon and applied it to an examination of the measurement problem. The innovation management process consisting of seven categories: inputs management, knowledge management, innovation strategy, organizational culture and structure, portfolio management, project management and commercialization as table 1.

\begin{tabular}{|c|c|}
\hline Framework category & Measurement areas \\
\hline Inputs & $\begin{array}{l}\text { People } \\
\text { Physical and financial resources } \\
\text { Tools }\end{array}$ \\
\hline $\begin{array}{l}\text { Knowledge } \\
\text { management }\end{array}$ & $\begin{array}{l}\text { Idea generation } \\
\text { Knowledge repository } \\
\text { Information flows }\end{array}$ \\
\hline Innovation strategy & $\begin{array}{l}\text { Strategic orientation } \\
\text { Strategic leadership }\end{array}$ \\
\hline $\begin{array}{l}\text { Organization and } \\
\text { culture }\end{array}$ & $\begin{array}{l}\text { Culture } \\
\text { Structure }\end{array}$ \\
\hline $\begin{array}{l}\text { Portfolio } \\
\text { management }\end{array}$ & $\begin{array}{l}\text { Risk/return balance } \\
\text { Optimization tool use }\end{array}$ \\
\hline Project management & $\begin{array}{l}\text { Project efficiency } \\
\text { Tools } \\
\text { Communications } \\
\text { Collaboration }\end{array}$ \\
\hline Commercialization & $\begin{array}{l}\text { Market research } \\
\text { Market testing } \\
\text { Marketing and sales }\end{array}$ \\
\hline
\end{tabular}

An integration between project management processes and innovation management concepts and components was developed; since project management alone cannot support radical innovation projects. Fig. 5 shows the mapping between PMBok process including initiating, planning, execution, controlling and closing phases with Innovation methodology process groups that consist of problem definition, critical analysis, solution development, validation \& decision, governance, detailed design, implementation, and 
optimization. This supports in revealing important innovation project successes and sustain companies development and competitive advantage [5].

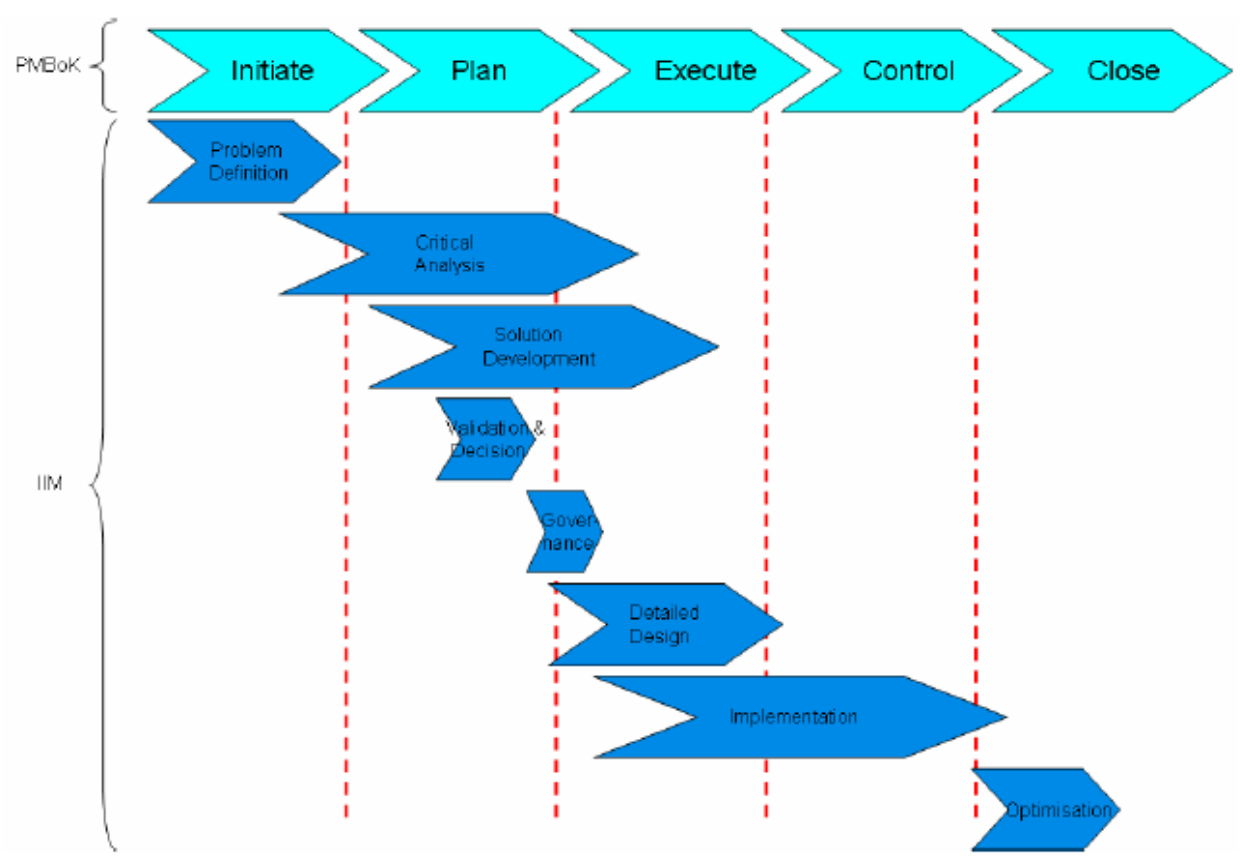

Fig. 5. Integration of the PM and IIM components [5]

After that, a model was developed for four common mmanagement practices for innovation projects consist of planning, senior management support, multidisciplinary teams, and heavyweight project leaders, and the influence of these practices on project performance. Moreover, the characteristics of project-based firms are investigated, how these affect management practices for innovation projects, and the influence of these practices on project performance. the firm characteristics consist of project-based firm, collaboration level, autonomy level, service firm, firm size, and firm strategy. Then the project characteristics consist of newness, planning, project autonomy, multidisciplinary team, and senior management support [9]. See Fig. 6.

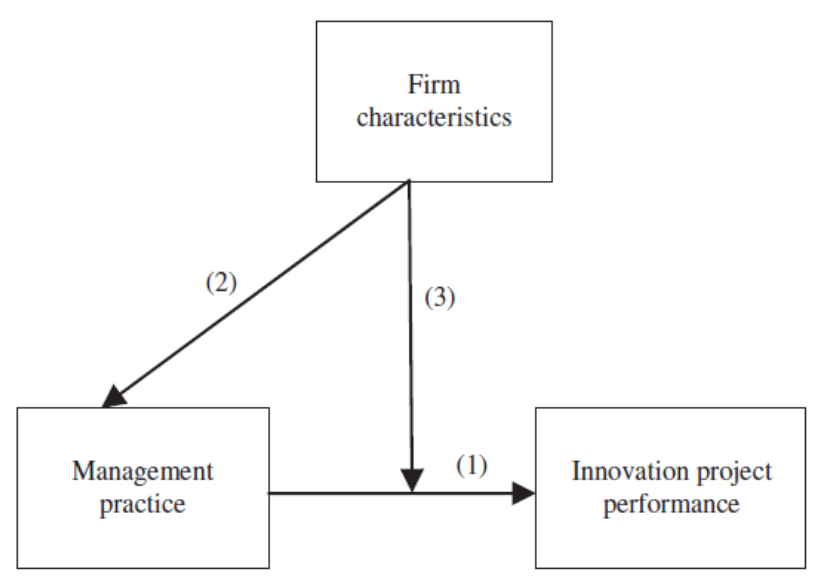

Fig. 6. Firm characteristics influence on the innovation project management practices [9]

Moreover, an innovative framework was designed for project management, which included innovation processes to enhance the project management processes. This framework described a structured method to integrate integration innovation management processes with project management processes. Project management processes take account of the five Course Clusters: Initiating, Planning, Executing, Monitoring and Controlling, and Closing, as cleared in PMBOK® Guide. Importance is given to scope management, human resource management, opportunity management, and requirements management processes. 
Equally, innovation processes contain discovery (ideas for solutions), open innovation (all possible ideas and solutions that can be an opportunities for innovative processes, products, or services), seek innovation partners (all stakeholders), idea management (create and evaluate all ideas, converge into one solution), knowledge brokering (sustain innovation), and innovation opportunity management [25].

Besides, a conceptual framework was created where they integrated strategic project management for product innovation projects, through business model, resource-based view, value proposition, contingency theory and dynamic capability theory. These strategies aimed at business value creation and enhancing the commercial product innovation achievement. The Strategy Project Management framework is essentially an input-output process, as shown in Fig. 7, and it illustrates that project managers should analyse [24]:

- Firm-level strategy and capabilities

- Internal project characteristics and external contingencies

- Project-level resources and capabilities

- Key project success factors

- Expectations to project value deliverables

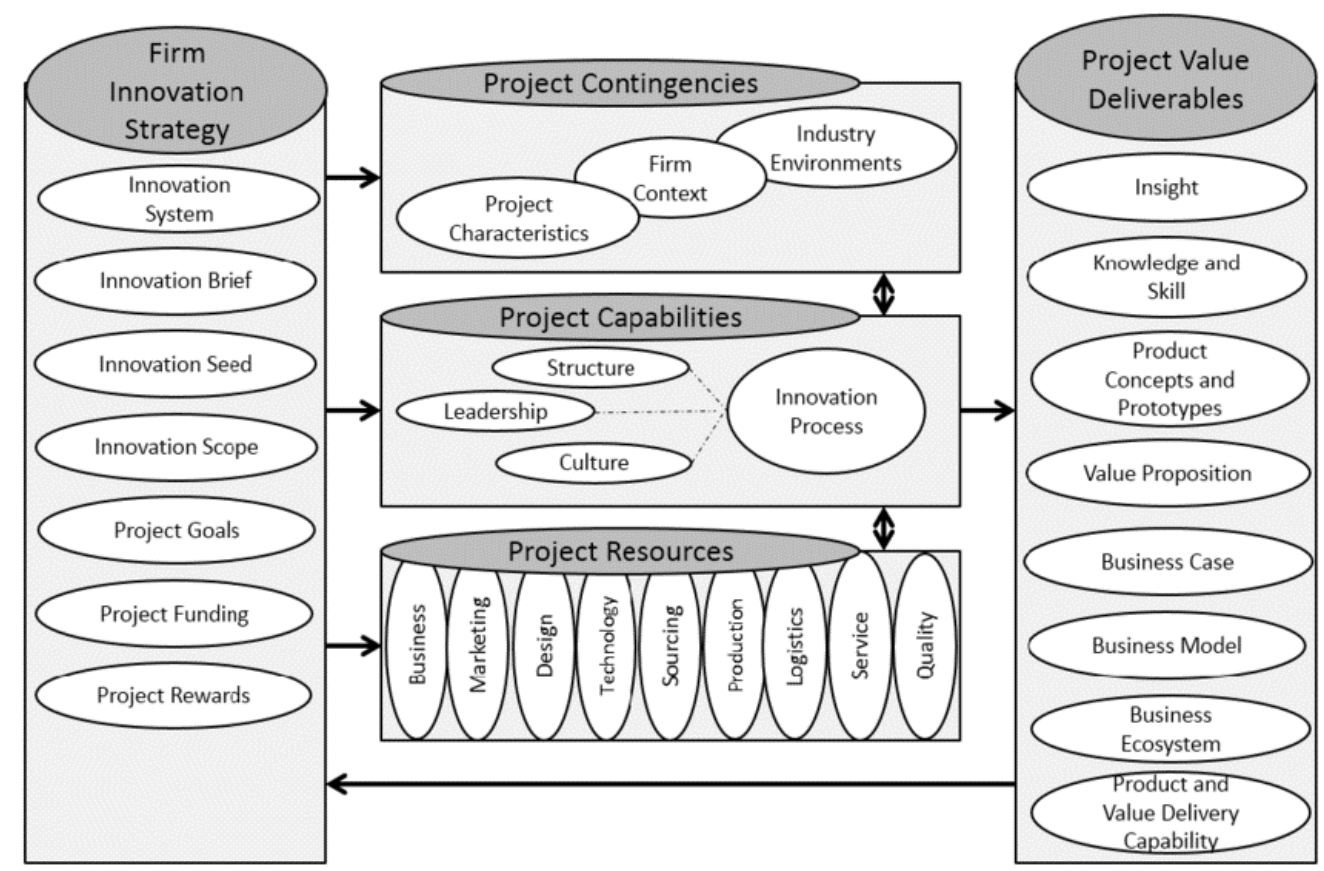

Fig. 7. The Strategy Project Management framework [24]

Then, [26] presented a paper about the innovation project tool, which aims to outline the main characteristics of innovation projects in terms of project management, then to use these facts for developing a tool for categorisation of innovation projects. These specific characteristics of innovation projects are defined thorough usage of knowledge areas of PMBOK project management methodology. Moreover, the findings were ranked the most ten innovation factors; and used them for testing the Innovation project tool.

\section{Research framework}

Based on a comprehensive literature review done in this paper, the proposed framework is established, which attempted to contribute in improvement of the innovation projects performance; in order to support project managers and innovation managers to facilitate their tasks. 
The proposed framework, as shown in Fig. 8, contains of dimensions related to innovation and project management aspects that consist of:

- Company innovation strategy refers to strategic orientation and strategic leadership [11,22].

- External innovation factors refers to characteristics of the sector and the commercialization [11,22].

- Internal innovation factors refers to size, services, technologies, collaboration and staff member $[11,9]$.

- Company innovation culture [11,12,22].

- Company structure [3,11,22].

- Innovation stakeholders refers to all innovation partners [25].

- Innovation tools refers to all tools needed for innovation like [11].

- Artificial intelligent refers to technological innovations [2].

- Knowledge management refers to idea generation, knowledge repository, and information flows $[17,18,22]$.

- Project inputs refers to people, physical and financial resources, communication, technology and tools $[22,24]$.

- Project characteristics refers to newness, planning, project autonomy, multidisciplinary team and senior management support [9,24].

- Project capabilities refers to project structure, project leadership, and project culture $[25,24]$.

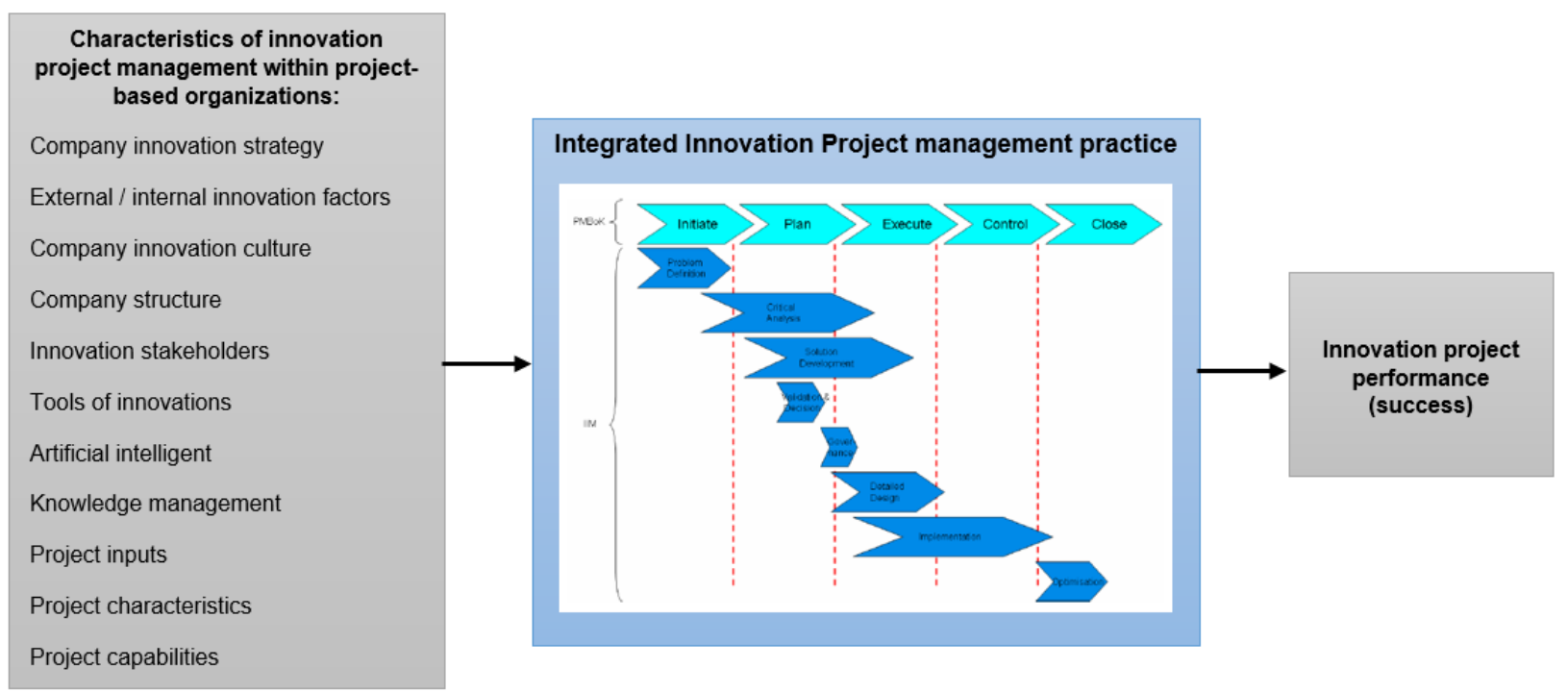

Fig. 8. The proposed conceptual framework

These twelve characteristics/dimensions had impact on the integrated innovation project management practice that leads to enhance the innovation project performance. Where the integrated innovation project management is an arrangement of project management stages with innovation management approach adopted from authors like $[17,25,26]$.

\section{Research methodology}

To test the paper's proposed conceptual framework, a cross-industry sample of firms in UAE will be utilized. Where, a deductive quantitative approach based on a proportionate stratified random sampling technique will be used. Therefore, an administrative on-line survey will be sent to the main members of the project management from internal interested party of these companies. The components that need to investigated are: The characteristics of innovation project management, as an (independent variables) measuring: company innovation strategy, externa/internal innovation factors, company innovation culture, company structure, innovation stakeholders, innovation tools, artificial intelligent, knowledge management, project inputs, project characteristics, and project capabilities. The integrated innovation project management 
practice as an (independent variables). The innovation project performance (success) as a (dependent variable) measuring: the external market-related performance, to capture the match with client needs, the impact of the innovation on competitive advantage, adherence to revenue targets, and adherence to profit targets, and the area of the new product or new service.

\section{Conclusions and future work}

As projects became the best chance to innovate, more than any time in history, as well as, projects were intended to change the business by nature. And since projects are no longer simply considered as operational actions. Thus, they are now very strongly contribute in enabling changes from a current state to a future state [12].

As a result, this paper developed a robust innovation framework for project management for project-based organizations. In which, innovation processes has been integrated with project development/management processes that can significantly leads to enhance the innovation in project-based organization, which as a results will achieve all the organizational short-term and long-term goals and realize a competitive benefits for the business. The innovation project management framework provides a structured approach for project managers to use in starting and delivering innovation projects with considering the entire related characteristic around the innovation project management aspect.

Finally, in future, extra investigation is required for project management approach to innovation, and to embed flexibility in innovation project management approaches. Moreover, considering that at this stage the present project management practice does not have enough or robust characteristics of innovation, so there is a need to identify further characteristics of innovation. Another suggestion is to use the agile concept in project management approach. Finally, it would be very valuable to have researches that are more empirical on the usage in other types of industries and different innovation projects [6].

\section{Acknowledgements}

We thank all those anonymous referees for their useful suggestions and helping to publish this work.

\section{References}

[1] Kalimullin, V. Yungblud and E. Khodyreva, "Characteristic Features of Innovation Project Management Aimed at University Human Resource Development", International journal of environemental \& Science education, vol. 11, no. 9, pp. 2237-2253, 2016. https://doi.org/10.12973/ijese.2016.601a.

[2] Khan, O. Aboud and S. Faisal, "An Empirical Study of Technological Innovations in the Field of Accounting - Boon or Bane", Business and Management Studies, vol. 4, no. 1, pp. 51, 2018. https://doi.org/10.11114/bms.v4i1.3057.

[3] Keegan and J. Turner, "The Management of Innovation in Project-Based Firms", Long Range Planning, vol. 35, no. 4, pp. 367-388, 2002. https://doi.org/10.1016/s0024-6301(02)00069-9.

[4] Bossink, "Effectiveness of innovation leadership styles: a manager's influence on ecological innovation in construction projects", Construction Innovation, vol. 4, no. 4, pp. 211-228, 2004. https://doi.org/10.1108/14714170410815105.

[5] Katz, "The integration of project management processes with a methodology to manage a radical innovation project", University of Stellenbosch, 2007.

[6] Ćirić, B. Lalić and D. Gračanin, "Managing Innovation: Are Project Management Methods Enemies or Allies", International Journal of Industrial Engineering and Management (IJIEM), vol. 7 no 1, pp. 31-4, 2016. Available: www.iim.ftn.uns.ac.rs/ijiem_journal.php.

[7] Gann and A. Salter, "Innovation in project-based, service-enhanced firms: the construction of complex products and systems", Research Policy, vol. 29, no. 7-8, pp. 955-972, 2000. https://doi.org/10.1016/s0048-7333(00)00114-1.

[8] Chell and R. Athayde, "The identification and measurement of innovative characteristics of young people Development of the Youth Innovation Skills Measurement Tool", Kingston University, NESTA, 2009. Available: www.nesta.org.uk.

[9] Blindenbach-Driessen and J. Van Den Ende, "Innovation Management Practices Compared: The Example of Project-Based Firms ${ }^{\star \prime}$, Journal of Product Innovation Management, vol. 27, no. 5, pp. 705-724, 2010. https://doi.org/10.1111/j.15405885.2010.00746.x.

[10] Ahmady, A. Nikooravesh and M. Mehrpour, "Effect of Organizational Culture on knowledge Management Based on Denison Model", Procedia - Social and Behavioral Sciences, vol. 230, pp. 387-395, 2016. https://doi.org/10.1016/j.sbspro.2016.09.049.

[11] G. Girmscheid and J. Bärthel, "Innovation management in construction companies: an integrated model" Performance in product and practice, CIB World Building Congress, Wellington, New Zealand, 2001.

[12] Kerzner, Innovation project management. John Wiley \& Sons, 2019.

[13] Bessant, A. Alexander, G. Tsekouras, H. Rush and R. Lamming, "Developing innovation capability through learning networks", Journal of Economic Geography, vol. 12, no. 5, pp. 1087-1112, 2012. https://doi.org/10.1093/jeg/lbs026.

[14] Bowers and A. Khorakian, "Integrating risk management in the innovation project", European Journal of Innovation Management, vol. 17, no. 1, pp. 25-40, 2014. https://doi.org/10.1108/ejim-01-2013-0010.

[15] J. Fagerberg and B. Verspagen, "Innovation studies-The emerging structure of a new scientific field", Research Policy, vol. 38, no. 2, pp. 218-233, 2009. https://doi.org/10.1016/j.respol.2008.12.006. 
[16] Bibarsov, G. Khokholova and D. Oklandnikova, "Conceptual Basics and Mechanism of Innovation Project Management", EUROPEAN RESEARCH STUDIES JOURNAL, vol., no. 2, pp. 224-235, 2017. https://doi.org/10.35808/ersj/675.

[17] K. Dalkir, Knowledge management in theory and practice. MIT press, 2017.

[18] Al-Hakim and S. Hassan, "core requirements of knowledge management implementation, innovation and organizational performance", Journal of Business Economics and Management, vol. 17, no. 1, pp. 109-124, 2016. https://doi.org/10.3846/16111699.2012.720597.

[19] Martinsuo, N. Hensman, K. Artto, J. Kujala and A. Jaafari, "Project-Based Management as an Organizational Innovation: Drivers, Changes, and Benefits of Adopting Project-Based Management", Project Management Journal, vol. 37, no. 3, pp. 87-97, 2006. https://doi.org/10.1177/875697280603700309.

[20] PMI, "A Guide to the project management body of knowledge, 6th ed", 14 Campus Boulevard, Newtown Square, Pennsylvania 19073-3299 USA: PMI, Inc, 2019.

[21] PMI, Al Innovators: Cracking the Code on Project Performance, 2019.

[22] R. Adams, J. Bessant and R. Phelps, "Innovation management measurement: A review", International Journal of Management Reviews, vol. 8, no. 1, pp. 21-47, 2006. https://doi.org/10.1111/j.1468-2370.2006.00119.x.

[23] S. Filippov and H. Mooi, "Innovation Project Management: a research agenda", Journal on Innovation and Sustainability, 2009. Available: http://revistas.pucsp.br/risus.

[24] T. Andersson and R. Chapman, "Project strategy for product innovation: the strategic project management framework", International Journal of Project Organisation and Management, vol. 9, no. 4, pp. 328, 2017. https://doi.org/10.1504/ijpom.2017.088240.

[25] V. Kumar, "Project managers as creative and innovative leaders", Paper presented at PMI® Global Congress 2012-North America, Vancouver, British Columbia, Canada. Newtown Square, 2012. PA: Project Management Institute.

[26] Z. Yordanova, "Innovation project tool for outlining innovation projects", International Journal of Business Innovation and Research, vol. 16, no. 1, pp. 63, 2018. https://doi.org/10.1504/ijbir.2018.091084. 